\title{
SHOCK INTERACTION CONTROL FOR SCRAMJET COWL LEADING EDGES
}

\author{
Cindy W. Albertson* \\ NASA-Langley Research Center \\ Hampton, Virginia 23681-2199 \\ Venki S. Venkat ${ }^{\dagger}$ \\ Analytical Services and Materials Inc. \\ Hampton, Virginia 23666-1340
}

\begin{abstract}
An experimental study was conducted to qualitatively determine the effectiveness of stagnation-region gas injection in protecting a scramjet cowl leading edge from the intense heating produced by Type III and Type IV shock interactions. The model consisted of a twodimensional leading edge, representative of that of a scramjet cowl. Tests were conducted at a nominal freestream Mach number of 6 . Gaseous nitrogen was supersonically injected through the leading-edge nozzles at various mass flux ratios and with the model pitched at angles of $0^{\circ}$ and $-20^{\circ}$ relative to the freestream flow. Qualitative data, in the form of focusing and conventional schlieren images, were obtained of the shock interaction patterns. Results indicate that large shock displacements can be achieved and both the Type III and IV interactions can be altered such that the interaction does not impinge on the leading edge surface.
\end{abstract}

\begin{tabular}{|c|c|c|c|}
\hline \multicolumn{4}{|c|}{ Nomenclature } \\
\hline & & $\operatorname{Re}$ & unit Reynolds number, $1 / \mathrm{ft}$. \\
\hline A & area, $\mathrm{in}^{2}$. & $\mathrm{s}$ & size of prescribed threshold, in. \\
\hline$b$ & spacing between dark & & (eq. 2) \\
\hline & bands on the cutoff grid, in. & $\mathrm{T}$ & temperature, ${ }^{\circ} \mathrm{R}$ \\
\hline CA & clear aperture, in. & V & velocity, ft./sec. \\
\hline $\begin{array}{l}\text { DU } \\
\text { FL }\end{array}$ & $\begin{array}{l}\text { depth of unsharp focus, in. (eq.2) } \\
\text { focal length, in. }\end{array}$ & w & $\begin{array}{l}\text { resolution of focusing schlieren } \\
\text { system, in. (eq. 1) }\end{array}$ \\
\hline $\mathrm{H}$ & height, in. & $X, Y$ & shock generator position relative to \\
\hline $\mathrm{Kn}_{\infty}$ & Knudson number, $(\gamma \pi / 2)^{1 / 2} M_{\infty} /\left(\operatorname{Re}_{\infty} r\right)$ & & model, in. (fig. 11) \\
\hline $\mathrm{L}$ & distance from the lens to the model & $\alpha$ & angle of attack, deg. \\
\hline & centerline, in. (fig. 9) & $\gamma$ & ratio of specific heats \\
\hline$L^{\prime}$ & distance from lens to the cutoff grid & $\lambda$ & wavelength of light, $\mathrm{nm}$ \\
\hline L" & $\begin{array}{l}\text { location, in. (fig. 9) } \\
\text { distance from lens to focal plane, in. }\end{array}$ & $\rho$ & density, $\mathrm{Ib}_{\mathrm{m}} / \mathrm{ft}^{3}$ \\
\hline & (fig. & Sub & ripts \\
\hline $\mathrm{m}$ & mass flux, $\mathrm{lb}_{\mathrm{m}} / \mathrm{sec}$ & J & gas jet \\
\hline & Mach number & le & leading edge \\
\hline a & magnification, L"/L & 0 & stagnation \\
\hline & pressure, psia & $\infty$ & freestream \\
\hline & approximate leading edge radius, & * & throat \\
\hline
\end{tabular}

*Senior Research Engineer, Hypersonic Airbreathing Propulsion Branch

${ }^{\dagger}$ Senior Research Engineer, Analytical Services and Materials Inc.

Copyright $\odot 2005$ by the American Institute of Aeronautics and Astronautics, Inc., No copyright is asserted in the United States under Title 17, U.S. Code. The U.S. Government has a royalty-free license to exercise all rights under the copyright claimed herein for governmental purposes. All other rights are reserved by the copyright owner. 


\section{Introduction}

The development of hypersonic vehicles presents a number of challenges to designers. High pressure and heating are expected to occur in areas of the vehicle subjected to shock interactions. Typical areas of concern are wing, tail, control surface compression corners, and axial corners created at wing/body surface junctions. For air-breathing vehicles, the engine cowl leading edge is of particular concern because of the desire to maximize engine thrust by maximizing air capture. This requires the vehicle to be designed and operated such that the compression shocks produced by the forebody ramps intersect the cowl leading edge (fig. 1). Unfortunately, these shocks can produce extremely high pressure and heating on the cowl leading edge, depending on where they intersect the cowl bow shock. The peak pressure and heating also depend on Mach number, Reynolds number, gas composition, and impinging shock strength.

The six basic shock interaction patterns were originally documented by Edney who conducted shock interaction experiments at Mach 4.6 and discussed the interactions in great detail. $^{1}$ The leading edge schematic (fig. 2) shows the approximate angular regions and the type of interaction pattern that occurs when a weak oblique shock wave interacts with the leading edge bow shock. Three of the interaction types (I, II, and V) result in shock-wave/boundary-layer interactions. A Type III interaction results in an attaching shear layer that produces high, localized pressure and heating depending on the state of the impinging shear layer. A Type VI interaction results in an expansion-fan/boundary-layer interaction. The most severe type of shock interaction is the Type IV interaction, which occurs when an oblique shock wave intersects near the normal portion of a bow shock, producing a supersonic jet that impinges on the leading edge. The maximum pressure and heating rate occur when the jet impinges perpendicular to the leading edge surface. (Readers interested in predicting peak pressures and heating rates for the various interactions are referred to the work of Glass. ${ }^{2}$ )

Wieting $^{3}$ and Holden ${ }^{4}$ tested cylindrical models representing the leading edge of a rectangular inlet from Mach 6 to 19. Their results show that the peak heating resulting from a Type IV interaction is as high as 30 times the undisturbed stagnation point heating at Mach 16 when the supersonic jet is turbulent. The amplification factor is even higher for multiple shock interactions, as shown in a later study by Wieting. ${ }^{5}$ Wieting's experiments at Mach 8 showed a $21 \%$ increase in heat transfer amplification for two coalesced oblique shock waves above that produced by a single oblique shock wave with the same flow turning angle.

Designing a cowl leading edge to withstand this intense heating is a formidable task. The heating rate gradients that occur over the narrow Type IV interaction region ${ }^{1,6}$ result in large wall temperature gradients, producing large thermal stresses. ${ }^{7}$ The Type IV interaction is often unsteady, ${ }^{3-5}$ producing oscillatory thermal stresses which limit the useful life of the leading edge. The experimental studies of Glass ${ }^{8}$ of cylindrical leading edge model in Mach 8 flow indicated that sweeping the edge reduced the peak heat flux for a Type IV interaction by a factor equal to the cosine of the sweep angle raised to the power of 2.2. Glass found that a 15 and $30^{\circ}$ sweep will reduce the peak heat flux by 7 and 27 percent, respectively.

Recent efforts to mitigate Type IV interaction heating have focused on controlling the shock interaction using various techniques. The computational study of Gaitonde ${ }^{9}$ focused on magnetogasdynamic (MGD) techniques, examining several electromagnetic configurations. The most successful configuration imposed a magnetic field (up to 7 Tesla) on the Mach 8 flow, pushing the bow shock forward so that the incident shock interacted with the bow shock in a slightly lower location, producing a Type III interaction which impinged on the leading edge surface. The maximum surface heat loads were reduced by $20 \%$. The study of Kandala, ${ }^{10}$ also computational, examined the effect of laser-induced energy deposition for a Type IV interaction in Mach 3.45 flow. The simulated laser pulse energy of $160 \mathrm{~mJ}$ was located at various positions upstream of the interaction. The resulting high temperature region temporarily changed the local Mach number, deformed the impinging shock, and traveled to the Type IV shock structure, temporarily increasing pressures and heating (about $10 \%$ and $20 \%$, respectively). The high temperature region then caused the bow shock to bulge, temporarily changing the interaction, which reduced impingement pressures and heating (over a period of $\sim 10$ micro seconds). 
A relatively simple method to alleviate the severe shock interference heating is to inject fluid into the stagnation region of the leading edge. In an experiment conducted by Nowak, ${ }^{11}$ the effect of transpiration cooling on reducing the surface heating produced by an impinging shock was studied. Gaseous helium was injected over most of the forward-facing surface of a hemispherical nose at Mach 12. The peak heating was only reduced by 8 percent for a transpiration mass flux of 31 percent of the freestream mass flux. (Note that in this study, the area used to calculate the freestream mass flux was the transpiration area (slot plus lands) projected on a plane normal to the model centerline). Nowak suggested that in order for the coolant to be more effective, it should be injected locally in the region of the shock interaction impingement. This is typically $20^{\circ}$ below the leading edge centerline ${ }^{4,11}$ for a Type IV interaction, however, the exact location is dependent on the variables discussed above.

There have been numerous studies of fluid injection (gas and liquid) in stagnation regions without external shock interference ${ }^{12-19}$. These studies indicate that fluid injection can significantly reduce heating ${ }^{12-14}$ and aerodynamic drag. ${ }^{15-17}$ Studies to examine the flow structure of a jet without external shock interference ${ }^{18,19}$ indicate that large shock displacements can be achieved. Bushnell and Huffman ${ }^{18}$ studied the effect of a forward facing jet of liquid water and liquid nitrogen on reducing radio attenuation during hypersonic flight at Mach 8 and 19.5. They found that liquid water had the greatest penetration, resulting in an oblique shock wave pattern in most cases.

This idea of locally injecting a forward-facing gas jet to alter the Type IV interaction was computationally studied by Prabhu, ${ }^{20}$ who modeled Mach 8 flow disturbed by an oblique shock upstream of two-dimensional cylindrical leading edge both with and without a single Mach 3 gas jet. Both the jet and freestream flow consisted of air modeled as a perfect gas with a constant specific heat ratio of 1.4. The ratio of jet mass flux to freestream mass flux was 0.337 (momentum ratio of 0.253 ), where the area used to calculate freestream mass flux was the projected surface area of the cylinder. The gas jet was injected into the flow at both the leading edge centerline $\left(0^{\circ}\right)$ and opposing the Type IV supersonic jet $\left(-20^{\circ}\right)$. For both cases, the shock interaction was altered such that the peak heating was reduced by about $30 \%$, although in both cases the modified interaction appeared to impinge on the leading edge. They recommend more detailed computational grids to better quantify heat transfer reduction and also optimizing the location and number of gas jets, jet mass flux, and jet Mach number.

The present experimental study was conducted to qualitatively determine the effectiveness of stagnation-region gas injection in protecting a scramjet cowl leading edge from the large aerothermodynamic loads produced by Type III and Type IV shock interactions. The model used for the study was designed and fabricated during the National Aero-Space Plane (NASP) program by Aero-Thermal Systems and Structures (ATSS) under contract with WrightPatterson Air Force Base. ${ }^{21}$ This model simulated a blunt, two-dimensional cowl leading-edge section fabricated with four rows of gas jet nozzles. The model was tested at a nominal freestream Mach number of 6 . Gaseous nitrogen was supersonically injected through the leading-edge nozzles at various mass flux ratios and with the model pitched at angles of $0^{\circ}$ and $-20^{\circ}$ relative to the freestream flow. Tests were conducted both with and without gas injection. During the tests, the two-dimensional shock generator vertically traversed the flow to produce Type III and IV shock interactions. Because one of the main objectives of the ATSS contract was to produce a prototype leading edge that approximated the design radius $(\sim 0.1 \mathrm{in}$.) of the NASP scramjet cowl leading edge, it was impractical to locate surface pressure and heat transfer instrumentation on the model. Therefore, qualitative data, in the form of focusing and conventional schlieren images, were obtained of the shock interaction patterns to evaluate the effectiveness of the gas jets in preventing a Type III shear layer and Type IV supersonic jet from impinging on the model surface.

\section{Description of Experiment}

\section{Model and Shock Generator}

A photograph of the cowl leading edge model is shown in figure 3 , along with some of the foils used in its fabrication. The model was fabricated by diffusion bonding 0.010 in. thick 347 stainless steel foils onto a 347 stainless steel "knife blade" support structure (fig. 4a). Some of 
the foils were etched, using a chemical etching process, to form internal coolant passages for both the convective cooling and gas jet circuits. (Only the gas jet circuits were used during the present study.) The model was designed with four rows of gas jet nozzles, with two rows located above and two below the model centerline and inclined at $5^{\circ}$ towards the centerline. These nozzles measured approximately $0.035 \mathrm{in}$. wide and $0.005 \mathrm{in}$. high at the nozzle exit plane (fig. $4 \mathrm{~b})$, and were designed with an area ratio, $A / A^{*}$, of 2.92. The corresponding isentropic exit Mach number of the nozzles is 2.6 for gaseous nitrogen. A photograph of the leading edge showing the nozzles is given in fig. 5. The overall length and width of the model was $1.90 \mathrm{in}$. and $1.50 \mathrm{in}$., respectively (fig. 6 ), which was sized to produce a region of two-dimensional flow near the center of the leading edge. Note that the leading edge was not cylindrical, but consisted of a small forward-facing flat surface, a $45^{\circ}$ circular arc, and a $45^{\circ}$ flat surface (fig. 6 ). This geometry was chosen to simplify the alignment of the convective cooling and gas jet circuits during the diffusion bonding process. Additional details of the model and its fabrication are given in reference 21.

A photograph of the model and shock generator installed in the test section of the NASA Langley 15-Inch Mach 6 High Temperature Tunnel (15" M6 HTT), is shown in fig. 7. Also shown in the figure is the shock generator with a $6^{\circ}$ wedge angle that was motorized to vertically traverse the flow at a maximum rate of 0.005 in. per second and produce the shock interaction. The leading edge of the shock generator had a 0.005 in. radius and the width matched that of the model (1.50 in.) A linear variable differential transformer was installed within the shock generator mechanism so that the vertical position of the shock generator relative to the model could be determined.

\section{Gas Supply System}

Gaseous nitrogen (chosen for availability and safety reasons) was supplied to the model from a nitrogen bottlefield consisting of $12 \mathrm{~K}$-size cylinders (fig. 8). Prior to the run, the regulator valve was used to set the desired line pressure. Then the solenoid valve was opened to allow the nitrogen to flow to the model. A 7 micron filter was located in the line to avoid clogging the small coolant passages within the model. The differential pressure transducer illustrated in the figure was used to check for clogging of the filter. A turbine flowmeter, located downstream of the filter, was used to determine volumetric flowrate. Pressure and temperature were measured downstream of the flowmeter to determine the mass flow rates.

\section{Flow Visualization}

The focusing schlieren system shown in figure 9 was specifically designed to obtain flowfield images for the present study. Distances between various components and lens characteristics, in terms of clear aperture, CA, and focal length, FL, are indicated in the figure. Unlike conventional schlieren systems in which a single light source and knife-edge are used, a focusing schlieren system uses a combination of multiple sources and multiple knife-edges. At the focal plane, the multiple images of a particular flowfield plane overlap, producing a focused image of the flow. Meanwhile, flow features on either side of the focal plane appear blurred. (Additional details of the governing principles are given in references 22-24.) For the present system, the multiple light sources were produced by illuminating a source grid, which consisted of multiple clear and dark bands. The extended light source used to illuminate the source grid consisted of a pulsed $30 \mathrm{~mJ} \mathrm{Nd}$ : YAG laser, a ground glass diffuser, and a Fresnel lens. The laser had a pulse duration of approximately 10 nanoseconds and was chosen to freeze any motion in the shock system in order to prevent blurring of the images. The laser was also chosen for its high intensity, which was necessary because approximately $90 \%$ of the light was blocked by the source grid. The laser was operated with a frequency doubling crystal, producing visible (green) light $(\lambda=532 \mathrm{~nm})$. These components were mounted on an optical bench and located on one side of the test section. The receiving optics consisted of a 24 in. focal length, 4 in. clear aperture lens, a cutoff grid to block out the undeflected light, a planar convex (PCX) lens downstream of the cutoff grid, and a beam splitter. A $70 \mathrm{~mm}$ motion picture camera and a black and white video camera were located downstream of the beam splitter to record the schlieren images.

by Weinstein: ${ }^{22}$

The resolution of the system, w, was estimated to be 0.005 in. using the equation given 


$$
w=2\left(L^{\prime \prime}-L^{\prime}\right) \lambda / M_{g} b
$$

In equation (1), L" is the distance from the 4 in. lens to the focal plane, $L$ ' is the distance from the $4 \mathrm{in}$. lens to the cutoff grid location, $\lambda$ is the wavelength of the light source, $M g$ is the magnification (defined as $L " / L$, where $L$ is the distance from the model centerline to the 4 in. lens), and $b$ is the spacing between dark bands on the cutoff grid ( 0.13 in.).

The "depth-of-unsharp focus" of the system, defined as the distance at which the loss of resolution exceeds a prescribed threshold, was determined by using the equation given by Weinstein: ${ }^{22}$

$$
\mathrm{DU}=2(\mathrm{~L} / \mathrm{CA}) \mathrm{s}
$$

In equation (2), CA is the clear aperture of the lens (4 in.), and $s$ is the size of prescribed threshold. If $1 \mathrm{~mm}(0.039 \mathrm{in}$.) is chosen for $\mathrm{s}$, then $\mathrm{DU}=0.79 \mathrm{in}$., where $\mathrm{DU}$ is measured from the focal plane, or model centerline in this case, outward. In general, the smaller the DU, the less flow three-dimensionality is visible in the schlieren image. The depth of unsharp focus for the system was impacted by the width of the test section (72 inches), because of the difficulty in locating the $4 \mathrm{in}$. lens inside the test section.

Unfortunately, the laser malfunctioned just before the last run during which the model was tested at $\alpha=-20^{\circ}$. Therefore, these flowfield images were obtained using the facility's conventional schlieren system.

\section{Test Facility}

The model was tested in the NASA Langley 15-Inch Mach 6 High Temperature Tunnel (15" M6 HTT), shown schematically in figure 10. This tunnel is a hypersonic blowdown facility that uses heated air as the test gas. High pressure air is supplied to the settling chamber from a 4450 psi air storage bottlefield. The air pressure is reduced by a 1800 psi reducing station and regulated to between 50 and 450 psi in the plenum. The air can be heated to a maximum stagnation temperature of approximately $1260^{\circ} \mathrm{R}$ by a $1.25 \mathrm{MW} \mathrm{AC}$ electrical resistance heater. The heated air is expanded through an axisymmetric nozzle to a nominal Mach number of 6 in the test section.

Once the target tunnel conditions are established, the model is injected from its retracted position to nozzle centerline using a hydraulic injection system. (Injection times range from 0.5 to 2.0 seconds.) The model injection system also provides the capability to vary angle of attack between -10 and $+50^{\circ}$. Windows are designed into the test section to provide optical access for flow visualization. Additional details of the facility can be found in reference 25 .

\section{Test Conditions and Procedure}

The tests were conducted at a total temperature of approximately $900^{\circ} \mathrm{R}$ and a nominal freestream Mach number of 6.0. The freestream unit Reynolds number ranged from $7.60 \times 10^{5}$ $\mathrm{ft}^{-1}$ to $4.34 \times 10^{6} \mathrm{ft}^{-1}$. The Knudsen number based on free stream conditions and leading edge radius, $\mathrm{Kn}_{\infty}$, ranged from 0.000187 to 0.00140 , which is well within the continuum range. ${ }^{26}$ Specific freestream flow conditions can be found in table 1. The mass flux ratio of the gas jet to the freestream flow ranged from 0.151 to 0.795 (table 2). Note that the freestream mass flow, $m_{\infty}$, is given as $m_{\infty}=\rho_{\infty} V_{\infty} A_{l e}$, where $A_{l e}$, the projected area, is equal to the projected height of the model leading edge, $\mathrm{H}_{\mathrm{le}}$, multiplied by the model width of 1.50 in. (fig. 6). The momentum flux ratio of the gas jet to the freestream flow is also given in table 2, based on an isentropic exit Mach number of 2.6 for the gas jet nozzles. Most of the tests were conducted with the model pitched at $0^{\circ}$ relative to the freestream flow, however, a single test was conducted with the model pitched at $-20^{\circ}$ so that the jets directly oppose the Type IV supersonic jet. This angle was chosen based on the results of Holden ${ }^{4}$ and Nowak, ${ }^{11}$ who observed that the maximum heating on their models occurred when the Type IV supersonic jet impinged the leading edge at approximately $20^{\circ}$ below the model centerline.

Once the tunnel flow conditions had been established, the model and shock generator were injected into the test stream. The shock generator was then moved vertically across the 
flow to produce various shock interaction patterns. The position of the shock generator relative to the model, in terms of $X$ and $Y$ coordinates (fig. 11), are given for each run in table 2. During most of the runs (runs 5 through 16), there was initially no flow from the gas jet nozzles. This was done to obtain baseline shock interaction images without the gas jets. Once the desired shock interaction pattern had been obtained, gaseous nitrogen was injected from the leading edge nozzles at a preset flow rate.

\section{Results and Discussion}

The results shown in the following sections were obtained at the highest nominal freestream unit Reynolds number of $4.16 \times 10^{6} \mathrm{ft}^{-1}$. This condition resulted in the highest flow density and hence the best schlieren images.

\section{Shock Wave Interaction Patterns without Gas Injection $\left(\mathrm{m}_{\mathrm{j}} / \mathrm{m}_{\infty}=\mathbf{0 . 0}\right)$}

Both Type III and Type IV shock interaction patterns were obtained without flow from the gas jet nozzles to serve as a baseline for comparing to interactions with gas injection. These interactions are described in the following sections.

Type III Interference Pattern. A Type III interference pattern occurs when a weak shock wave intersects the strong portion of a detached bow shock wave (fig. 12a). The shear layer emanating from the shock intersection point attaches to the leading edge surface. The flow in the region above the shear layer is subsonic and the flow between the shear layer and transmitted shock is supersonic. Pressure and heating amplification at the surface impingement site is caused by the attaching shear layer, analogous to a reattaching separated boundary layer. ${ }^{1}$ Amplification levels are dependent on Reynolds number (based on shear layer length) of the attaching shear layer and whether the shear layer is laminar or turbulent. A typical schlieren image of a Type III interaction on the leading edge model at $\alpha=0^{\circ}$ is shown in figure $12 \mathrm{~b}$. As expected, the Type III interaction transitioned to a Type IV interaction when the shock generator moved closer to the model.

Type IV Interference Pattern. A Type IV interference pattern occurs when a weak shock wave intersects the near the normal portion of the bow shock wave, as shown in figure 13 . The resulting flow pattern is characterized by a supersonic jet contained between two shear layers embedded in the subsonic flow behind the bow shock (fig. 14). A jet bow shock is produced where the jet impinges on the surface producing a highly localized region of stagnation heating.

During the present study, the supersonic jet produced by the Type IV interaction was observed to be unsteady, changing location where it intersects the model. This is illustrated by the schlieren images in figure 15 obtained 1.4 seconds apart with the shock generator at a fixed position. Unsteady Type IV jet behavior for the present model may be influenced by the leading edge geometry. As shown in fig. 6 , the forward portion of the model leading edge is not circular, but is octagonal. The present leading edge geometry does not have an extensive shock interaction data base as does the spherical and circular leading edge geometries. Note that results presented in fig. 15 show a dramatic change in the jet location.

The unsteady behavior of the Type IV jet was observed by Holden, ${ }^{3}$ for cylindrical geometries. Holden noted that the frequency of the oscillation was between $2 \mathrm{kHz}$ to $5 \mathrm{kHz}$, as inferred from heat transfer and pressure measurements. This behavior was investigated by Lind and Lewis ${ }^{26}$ who performed two-dimensional, time-accurate, computations of the Type IV interaction on a cylindrical geometry at Mach 8.1. Based on their results, they subdivided the Type IV interaction according to flow behavior (steady or unsteady) for three ranges of impinging shock locations:

- Type IV ${ }^{-}$: Shock intersection point $<-5^{\circ}$ below horizontal

- Type IV : Shock intersection point between $-5^{\circ}$ and $5^{\circ}$

- Type $\mathrm{IV}^{+}$: Shock intersection point $>5^{\circ}$ above horizontal 
Their results showed that Type $\mathrm{IV}^{+}$is steady, Type IV may be steady or unsteady, and Type IV ${ }^{-}$is unsteady. They further noted that the unsteadiness of the Type IV interaction is dependent upon the orientation of the terminating shock of the supersonic jet. If the terminating shock is oriented such that it is either parallel with the model surface or at an angle such that the flow through the shock is deflected downward, the interaction was found to be unsteady. The unsteadiness of the Type IV ${ }^{-}$interaction is associated with an unsteady separation region located above the jet impingement location.

A similar computational study using the present leading edge geometry is needed to better define the effect of geometry on the unsteady flow behavior.

\section{Shock Wave Interaction Patterns with Gas Injection}

High Mass Flux Ratio $\left(m_{j} / m_{\infty}=\mathbf{0 . 5 1}\right)$ After the shock generator was positioned to produce a Type IV interaction for the no gas injection case ( $Y=0.532$ in.), the solenoid valve of the gas supply system was opened, allowing gas to be supersonically injected at the stagnation region of the model leading edge. Once injection began, the bow shock was pushed away from the model surface, causing the incident shock to intersect the bow shock at a lower position. For the highest mass flux ratio of 0.51 , this results in the Type IV interaction transitioning to a modified shock interaction which resembles a Type III interaction, as shown in the focusing schlieren image in figure 16a. The average shock standoff distance, measured from the schlieren photographs along the model centerline, was increased by approximately 4 times the Type IV shock standoff distance without gas injection (henceforth referred to as the reference shock standoff distance). The resulting flow pattern is illustrated in figure 16b. The gas jets originating from the nose of the model lose their identity and merge into a large turbulent jet which is deflected upward by the modified interaction. The jet mixes with the freestream flow which crosses the model bow shock and then expands as it turns upward and around the model. In addition, the shear layer produced by the modified interaction is deflected down and away from the surface of the model.

The unsteady behavior of the modified Type III interaction with gas injection is illustrated by the focusing schlieren images shown in figure 17 with the shock generator at a fixed position. The unsteadiness may be caused by the gas jet as it became turbulent before exiting above the leading edge, resulting in fluctuations in the pressure field and corresponding fluctuations in the bow shock position. Note that the flow away from the model centerline appears out of focus, indicating that the unsteadiness is three-dimensional. The finite span of the model may influence the three-dimensional unsteady nature, however, its extent is uncertain. The frequency of the shock system unsteadiness could not be determined because of the relatively slow frame rate (30 $\mathrm{Hz}$ ) of the video camera.

As the shock generator moved closer to the model, the modified Type III shear layer also moved closer. This shear layer came closest to the model just before the flow transitioned to a modified Type IV interaction (fig. 18a). For this case, the shear layer was deflected away from the model leading edge by the secondary shock. As the shock generator moved even closer to the model $(Y=0.430$ in.), the incident shock intersected near the normal portion of the bow shock, producing a modified Type IV interaction (fig. 18b). Note that the gas jets deflected the Type IV supersonic jet away from the model surface, although the shock standoff distance is reduced to approximately 3 times the reference shock standoff distance, because of the high pressure of the Type IV jet. The details of this jet-on-jet interaction are unclear from the image. For future studies, the combination of a larger model and higher resolution camera would clarify the flow details. Again the shock system is observed to be unsteady, as illustrated by the images shown in figure 19 with the shock generator at a fixed position.

\section{Intermediate Mass Flux Ratio $\left(m_{j} / m_{\infty}=0.34\right)$}

In figures $20 \mathrm{a}$ and $20 \mathrm{~b}$, focusing schlieren images are shown just before and after transitioning from a modified Type III to modified Type IV interaction for an intermediate mass flux ratio of 0.34 . These images were selected because the modified Type III shear layer and modified Type IV supersonic jet were closest to the model when the incident shock intersects the bow shock near the Type III and IV interaction transition point. The flow behaved in a somewhat 
similar manner as with the higher mass flux ratio, except that the shock standoff distances are closer to the model. As a result, the Type III shear layer and Type IV supersonic jet are also closer to the model, although neither appear to impinge on the leading edge. Therefore, a mass flux ratio of 0.34 provides sufficient protection to the leading edge, although studies with surface measurements are needed to quantitatively determine the influence of the gas jets on surface heating.

\section{Low Mass Flux Ratio $\left(m_{j} / m_{\infty}=0.17\right)$}

At the lowest mass flux ratio of 0.17 , it appears that the modified Type III shear layer may impinge the leading edge near the corner of the lower $45^{\circ}$ slope and $5^{\circ}$ slope (fig. $21 \mathrm{a}$ ). As the shock generator moved closer, the interaction transitioned to a modified Type IV interaction (fig.21b). The supersonic jet produced by the modified Type IV interaction was deflected upward by the gas jets and appears to intersect the model surface at the corner between the normal portion of the model and the upper $45^{\circ}$ slope. These results indicate that for the present flow conditions, a mass flux ratio of approximately 0.34 or greater is necessary to avoid shear layer or supersonic jet impingement and the associated high interaction heating.

\section{$-20^{\circ}$ Model Angle of Attack}

An additional run (run 16) was conducted to study the effect of the gas jets directly opposing the supersonic jet produced by the Type IV interaction. The mass flux ratio was set at 0.34 , which was shown to be effective in deflecting the Type III shear layer and Type IV supersonic jet for a $0^{\circ}$ model angle of attack. For this run, a conventional schlieren system was used because the laser required for the focusing schlieren system failed, and a light source having sufficient brightness could not be obtained within the time frame of the tests. Unfortunately, this adversely affected the image quality, however, the image quality was improved by digital post-processing. The improvement is shown by comparing figures $22 \mathrm{a}$ and $22 \mathrm{~b}$.

When the gas was injected with the model at $\alpha=-20^{\circ}$, the bow shock standoff distance increased slightly, as shown in the close-up views in figures 23a and 23b. However, for the same nominal mass flux ratio of 0.34 , the shock standoff distance did not increase as much with the model at $\alpha=-20^{\circ}$ (fig. 23b) as observed with the model at $\alpha=0^{\circ}$ (fig. 20b). Unfortunately, the flow features are unclear in the images, and it is uncertain whether the Type IV supersonic jet impinged on the leading edge surface. These results indicate that the gas jets are more effective at $\alpha=0^{\circ}$, due to the high pressure encountered by the jets when they oppose the Type IV supersonic jet at $\alpha=-20^{\circ}$. Also these results indicate that a focusing system is needed to obtain the clearest images and avoid adverse effects inherent to conventional schlieren systems (such as test section window optical flaws, facility nozzle shear layers, and model edge flows) which obscure the images.

\section{Concluding Remarks}

An experimental study was conducted to determine if stagnation-region gas injection would sufficiently alter the flow to prevent Type III and IV shock interactions from impinging on a twodimensional leading edge model. The model was tested at a nominal freestream Mach number of 6 . Gaseous nitrogen was supersonically injected at various flow rates through the leading edge nozzles with the model pitched at $\alpha=0^{\circ}$ and $-20^{\circ}$. Qualitative data, in the form of focusing and conventional schlieren images, were obtained of the shock interaction patterns. Results indicate that large shock displacements can be achieved and both the Type III and IV interactions can be altered such that the interaction does not impinge on the leading edge surface. The results obtained at $\alpha=0^{\circ}$ indicate that the gas jets prevent the Type III and IV interactions from impinging on the model for jet-to-freestream mass flux ratios of 0.34 and above. The results also indicate that the gas jets are more effective in preventing interaction jet impingement on the surface at $\alpha=0^{\circ}$ than at $\alpha=-20^{\circ}$. The shock interaction patterns are observed to be unsteady, particularly at higher mass flux ratios. This may be caused by turbulence in the gas jet. These preliminary studies indicate that stagnation region gas injection can provide protection for scramjet cowl leading edges during flight conditions resulting in Type III and IV shock interactions. Additional studies are needed to optimize the nozzle geometry, quantify the 
reduction in leading edge heating, and determine the effect of freestream Mach number on the required mass flux ratio. Also, the effect of such forward-facing jets on scramjet inlet operability, combustion stability, and net thrust should be investigated and optimized.

\section{Acknowledgment}

The authors would like to acknowledge Dr. Leonard Weinstein for designing the focusing schlieren system and for his help in acquiring the necessary components.

\section{References}

1. Edney, Barry: "Anomalous Heat Transfer and Pressure Distributions on Blunt Bodies at Hypersonic Speeds in the Presence of an Impinging Shock," FFA Report 115, The Aeronautical Research Institute of Sweden, February, 1968.

2. Glass, C. E.: "Computer Program to Solve Two-Dimensional Shock-Wave Interference Problems with an Equilibrium Chemically Reacting air Model," NASA TM 4187, August, 1990.

3. Wieting, A. R.; and Holden, M. S.: "Experimental Study of Shock Wave Interference Heating on a Cylindrical Leading Edge at Mach 6 and 8," AIAA Paper 87-1511, June 1987.

4. Holden, M. S.; Wieting, A. R.; Moselle, J.R.; and Glass, C. E.: "Studies of Aerothermal Loads Generated in Regions of Shock/Shock Interaction in Hypersonic Flow," AIAA Paper 88-0477, January, 1988.

5. Wieting, A. R.: "Multiple Shock/Shock Interference on a Cylindrical Leading Edge," AIAA Paper 91-1800, June 1991.

6. Keyes, J. W.; and Hains, F. D.: "Analytical and Experimental Studies of Shock Interference Heating in Hypersonic Flow," NASA TN D-7139, May 1973.

7. Thornton, E. A.; and Pramote, E.: "A Taylor Galerkin Finite Element Algorithm for Transient Nonlinear Thermal-Structural Analysis," AIAA Paper 86-0911, 1986.

8. Glass, C. E.; Holden, M. S.; and Wieting, A. R.: "Effect of Leading Edge Sweep on Shock/Shock Interference at Mach 8," AIAA Paper 89-0271, January 1989.

9. Gaitonde, D. V.; and Miller, J. H.: "Numerical Exploration of Shock Interaction Control with Plasma-based Techniques," AIAA 2003-3483, June 2003.

10. Kandala, R.; and Candler, G. V.: "Numerical Studies of Laser-Induced Energy Deposition for Supersonic Flow Control," AIAA Journal, Vol. 42, No. 11, November 2004.

11. Nowak, R. J.; Holden, M. S.; and Wieting, A. R.: "Shock/Shock Interference on a Transpiration Cooled Hemispherical Model," AIAA Paper 90-1643, June 1990.

12. Beckwith, I. E.; and Bushnell, D. M.: "Effect of Intermittent Water Injection on Aerodynamic Heating of a Sphere-Cone at Flight Velocities to 18,000 feet per second," NASA TM X-1128, September 1965.

13. Nowak, R. J.: "Gas-Jet and Tangent-Slot Film Cooling Tests of a 12.5 degree Cone at Mach Number 6.7," NASA TP 2786, May 1988.

14. Warren, C. H.: "An Experimental Investigation of the Effect of Ejecting a Coolant Gas at the Nose of a Bluff Body," J. Fluid Mech., vol. 8, pt. 3, March 1960, pp. 400-417. 
15. Love, E. S.: "The Effects of a Small Jet of Air Exhausting from the Nose of a Body of Revolution in a Supersonic Flow," NACA RM L52I19a, November 1952.

16. Reding, J. P.; and Jecman, D. M.: "Drag Reduction via Hot Gas Injection," Lockheed Missiles and Space Company, TM 81-11/337, December 1985.

17. Pamadi, B. N.: "Forebody Drag Reduction," AIAA Journal, vol. 19, no. 10, October 1981, pp. 1370-1372.

18. Bushnell. D. M.; and Huffman, J. K.: "Forward Penetration of Liquid Water and Liquid Nitrogen Injected from an Orifice at the Stagnation Point of a Hemispherically Blunted Body in Hypersonic Flow," NASA TM X-1493, March 1968.

19. Romeo, D. J.; and Sterrett, J. R.: "Exploratory Investigation of the Effect of a ForwardFacing Jet on the Bow Shock of a Blunt Body in a Mach Number 6 Free Stream," NASA TN D-1605, 1963.

20. Prabhu, R. K.: Wieting, A. R.; and Tharaja, R. R.: "Computational Studies of a Fluid Spike as a Leading Edge Protection Device for Shock/Shock Interference Heating," AIAA Paper 91-1734, June 1991.

21. Moody, H. L.; and Campbell, G.O.: Hybrid Cowl Leading Edge for Hypersonic Flight Systems," Aero-Thermal Systems and Structures Report TR-SB-1025-01, April 1990.

22. Weinstein, L. M.: "An Improved Large-Field Focusing Schlieren System," AIAA Paper 910567, January 1991.

23. Burton, R. A. "A Modified Schlieren Apparatus for Large Areas of Field," Journal of the Optical Society of America, vol. 39, no. 11, November 1949, pp.907-908.

24. Fish, R. W.; and Parnham, K.: "Focusing Schlieren Systems," C. P. No. 54 (13.865), ARC Technical Report, Tech. Note No. IAP 999, November 1950.

25. Hodge, J. S.: "The Langley 15-Inch Mach 6 High Temperature Tunnel," AIAA Paper 923938, July 1992.

26. Eckert, E. R. G.; and Drake, R. M., Jr.: "Analysis of Heat and Mass Transfer." First ed. McGraw-Hill, Inc., c. 1972.

27. Lind, C. A.; and Lewis, M. J.: "Unsteady Effects of Hypersonic Type IV Shock Interaction," AIAA Paper 94-2945, June 1994.

\begin{tabular}{|c|c|c|c|c|c|c|c|c|}
\hline Run & $\mathrm{M}_{\infty}$ & $\mathrm{T}_{0},{ }^{\circ} \mathrm{R}$ & $\mathrm{T}_{\infty},{ }^{\circ} \mathrm{R}$ & $\mathrm{p}_{\mathrm{o}}, \mathrm{psia}$ & $\rho_{\infty}, \mathrm{lbm} / \mathrm{ft}^{3}$ & $\mathrm{~V}_{\infty}, \mathrm{ft} / \mathrm{s}$ & $\mathrm{q}_{\infty}, \mathrm{psf}$ & $\mathrm{Re}{ }_{\infty}, 1 / \mathrm{ft}$. \\
\hline & & & & & & & & \\
\hline 1 & 6.0 & 930. & 113. & 46.0 & $6.93 \mathrm{E}-04$ & 3126. & 105. & $7.60 \mathrm{E}+05$ \\
\hline 2 & 6.0 & 930. & 113. & 180. & $2.73 \mathrm{E}-03$ & 3126. & 414. & $3.03 \mathrm{E}+06$ \\
\hline 5 & 6.0 & 920. & 112. & 243. & $3.72 \mathrm{E}-03$ & 3112. & 559. & $4.14 \mathrm{E}+06$ \\
\hline 6 & 6.0 & 930. & 113. & 241. & $3.66 \mathrm{E}-03$ & 3126. & 555. & $4.06 \mathrm{E}+06$ \\
\hline 7 & 6.0 & 905. & 110. & 245. & $3.81 \mathrm{E}-03$ & 3085. & 563. & $4.31 \mathrm{E}+06$ \\
\hline 8 & 6.0 & 898. & 109. & 243. & $3.82 \mathrm{E}-03$ & 3071. & 559. & $4.34 \mathrm{E}+06$ \\
\hline 9 & 6.0 & 930. & 113. & 239. & $3.61 \mathrm{E}-03$ & 3126. & 548. & $4.00 \mathrm{E}+06$ \\
\hline 16 & 6.0 & 925. & 113. & 246. & $3.73 \mathrm{E}-03$ & 3126. & 566. & $4.13 \mathrm{E}+06$ \\
\hline
\end{tabular}

Table 1. Freestream conditions. 


\begin{tabular}{|c|c|c|c|c|c|c|c|c|c|c|c|}
\hline Run & $\alpha$, deg & $\mathrm{X}$, in. & $\mathrm{Y}$, in. & $\mathrm{M}_{\mathrm{j}}$ & $\mathrm{T}_{\mathrm{o}, \mathrm{j}},{ }^{\circ} \mathrm{R}$ & $\mathrm{p}_{\mathrm{o}, \mathrm{j}}, \mathrm{psia}$ & $\mathrm{m}_{\mathrm{j}}, \mathrm{Ibm} / \mathrm{s}$ & $\mathrm{m}_{\mathrm{j}} / \mathrm{m}_{\infty}$ & $\mathrm{V}_{\mathrm{j}} \mathrm{m}_{\mathrm{j}} / \mathrm{V}_{\infty} \mathrm{m}_{\infty}$ & Type III & Type IV \\
\hline & & & & & & & & & & & \\
\hline
\end{tabular}

Table 2. Shock position and jet conditions.

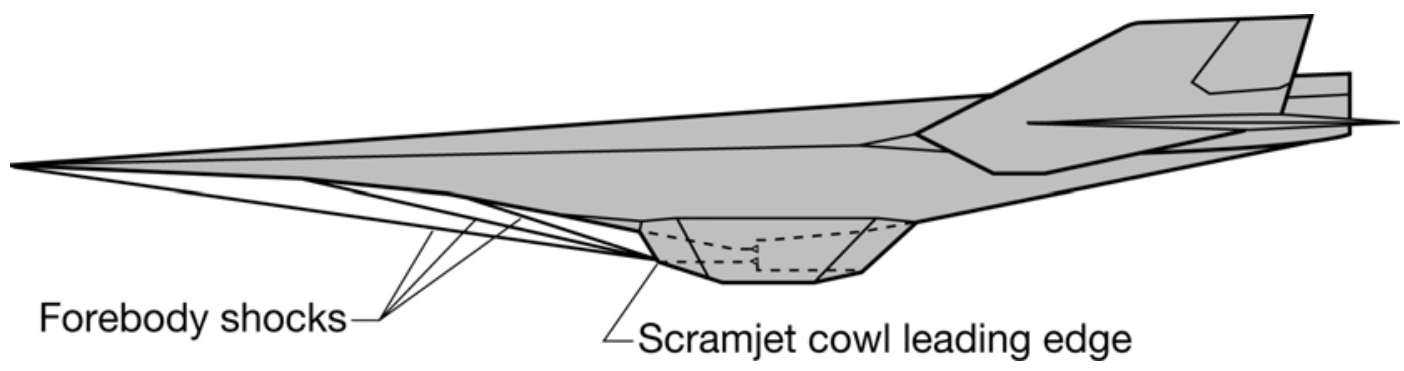

Figure 1. Shock interaction on the cowl leading edge of a hypersonic airbreathing vehicle.

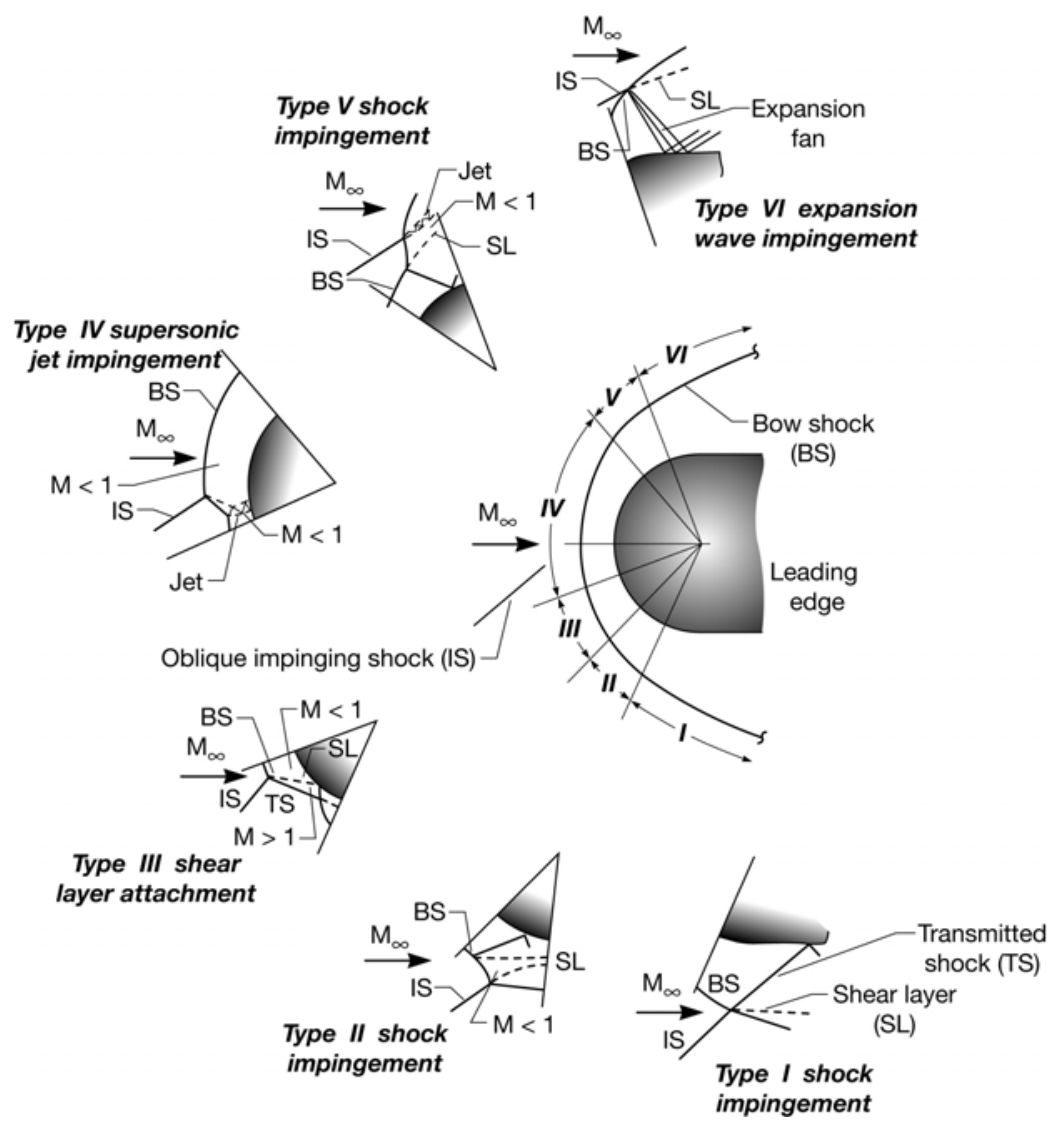

Figure 2. Six types of shock wave interference patterns and their locations on a blunt leading edge. 


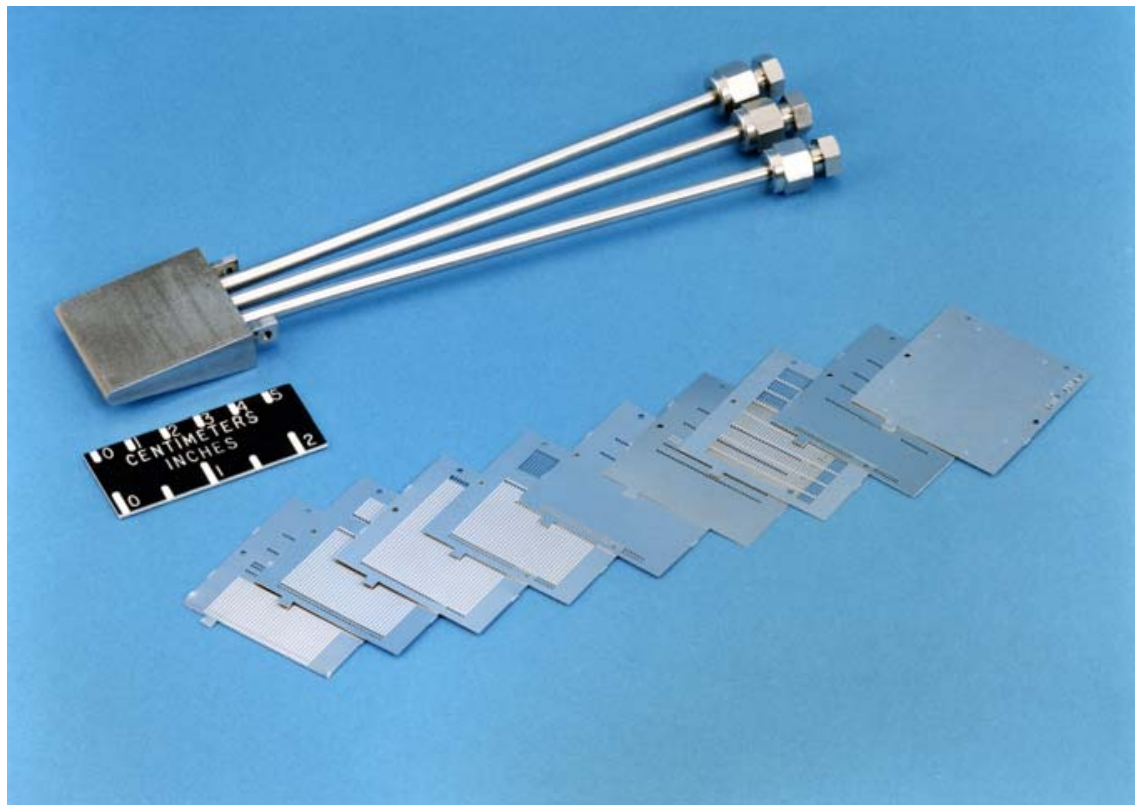

Figure 3. Completed cowl leading edge model shown with a spare set of stainless steel foils.

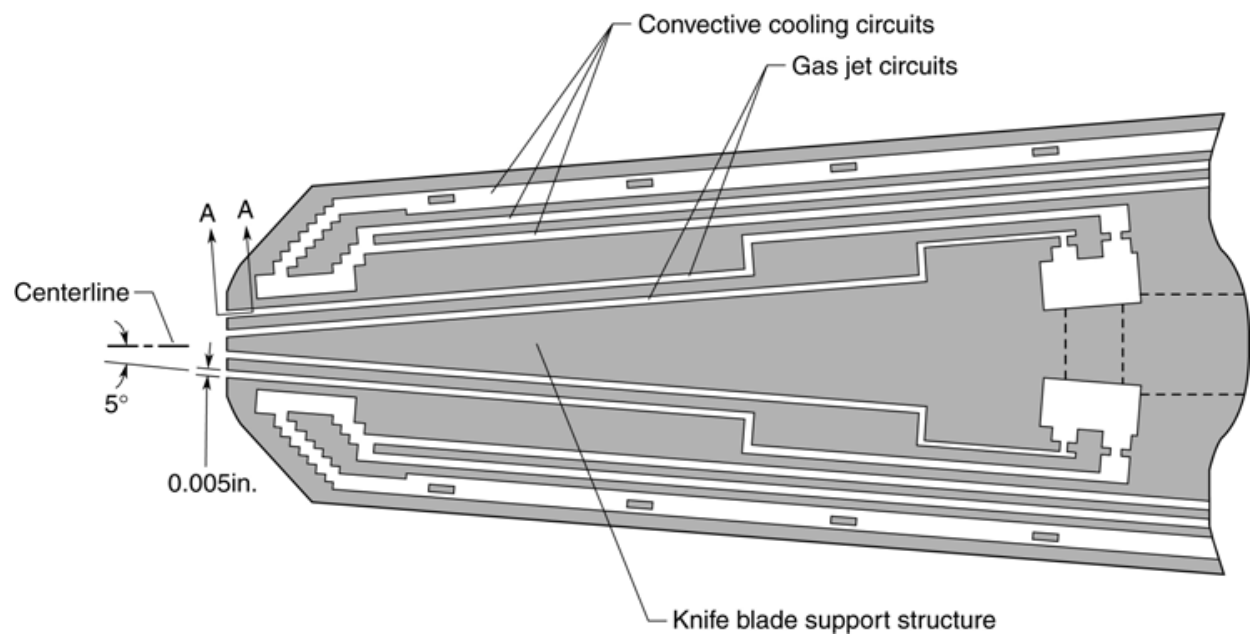

(a) Cowl leading edge region

Figure 4. Cross section of model showing gas jet and convective cooling circuits. 

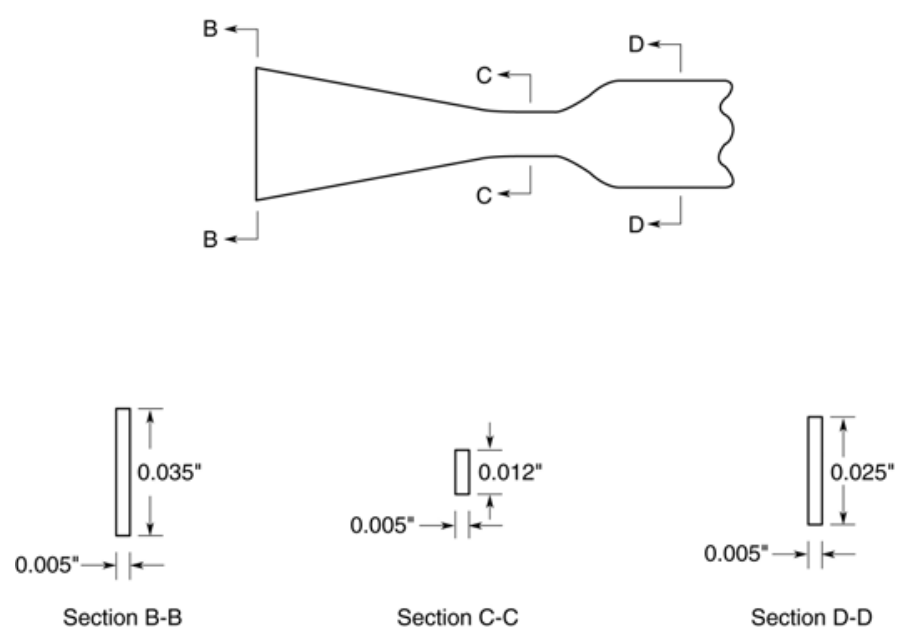

(b) Sectional details $(A-A)$

Figure 4.Concluded.

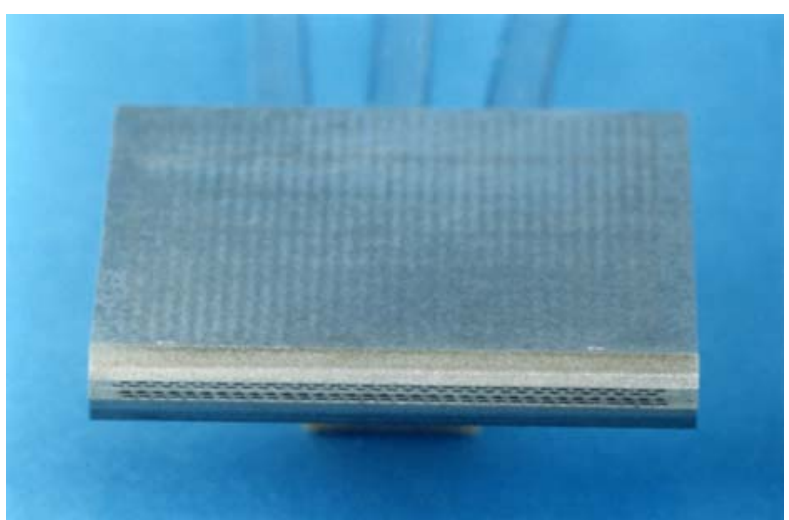

Figure 5. Front view of cowl leading edge model showing gas jet nozzles.
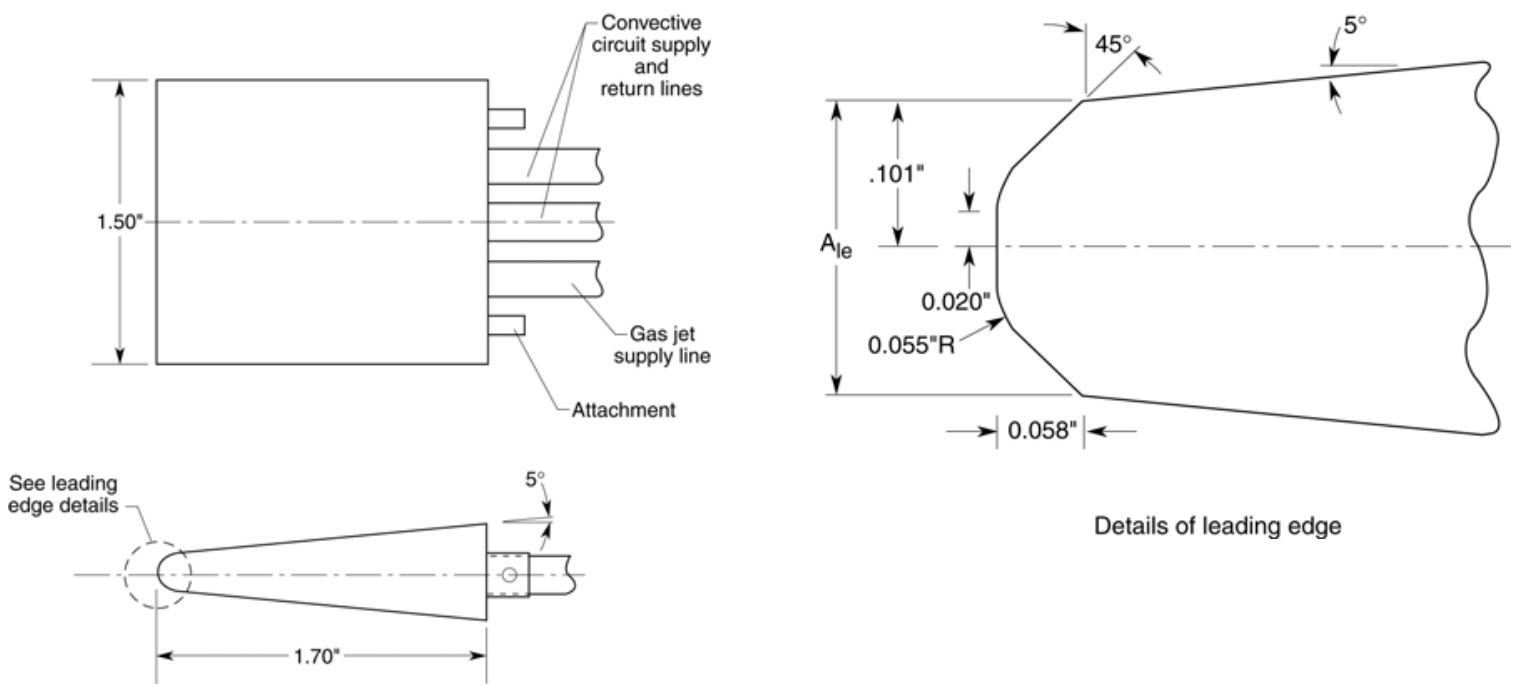

Details of leading edge

Figure 6. Schematic of cowl leading edge model. 


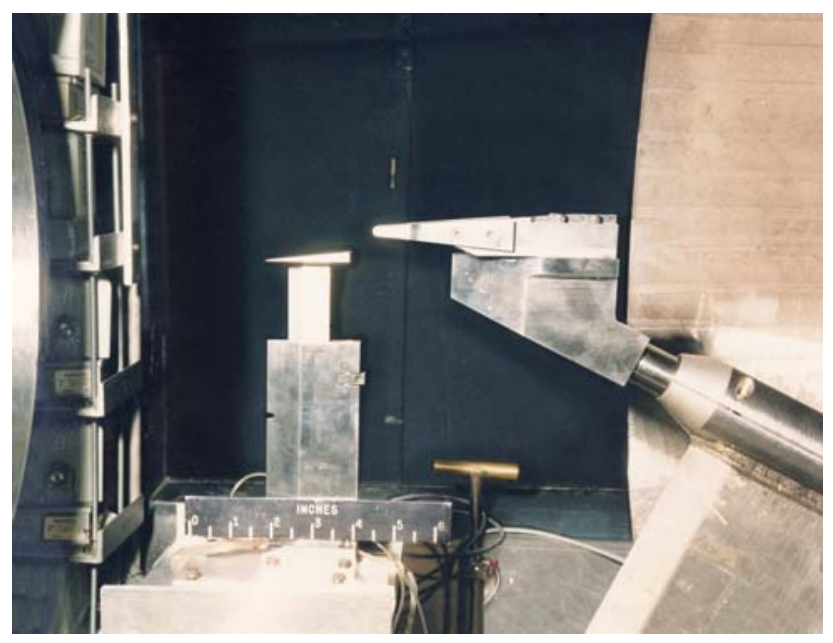

Figure 7. Model and shock generator installed in the test section of the NASA Langley 15-Inch Mach 6 High Temperature Tunnel.

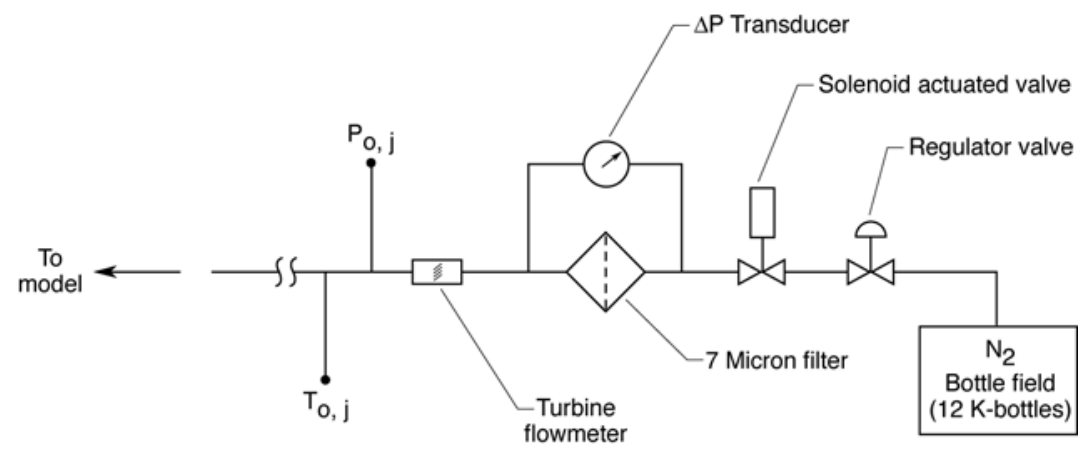

Figure 8. Model gas supply system.

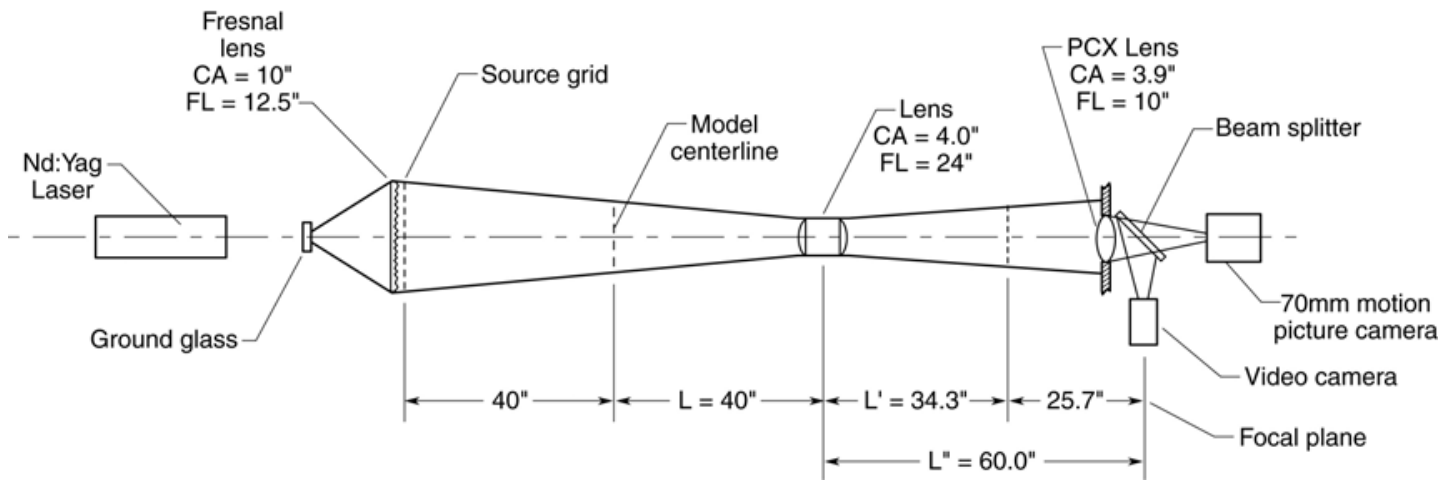

Figure 9. Focusing schlieren system. 


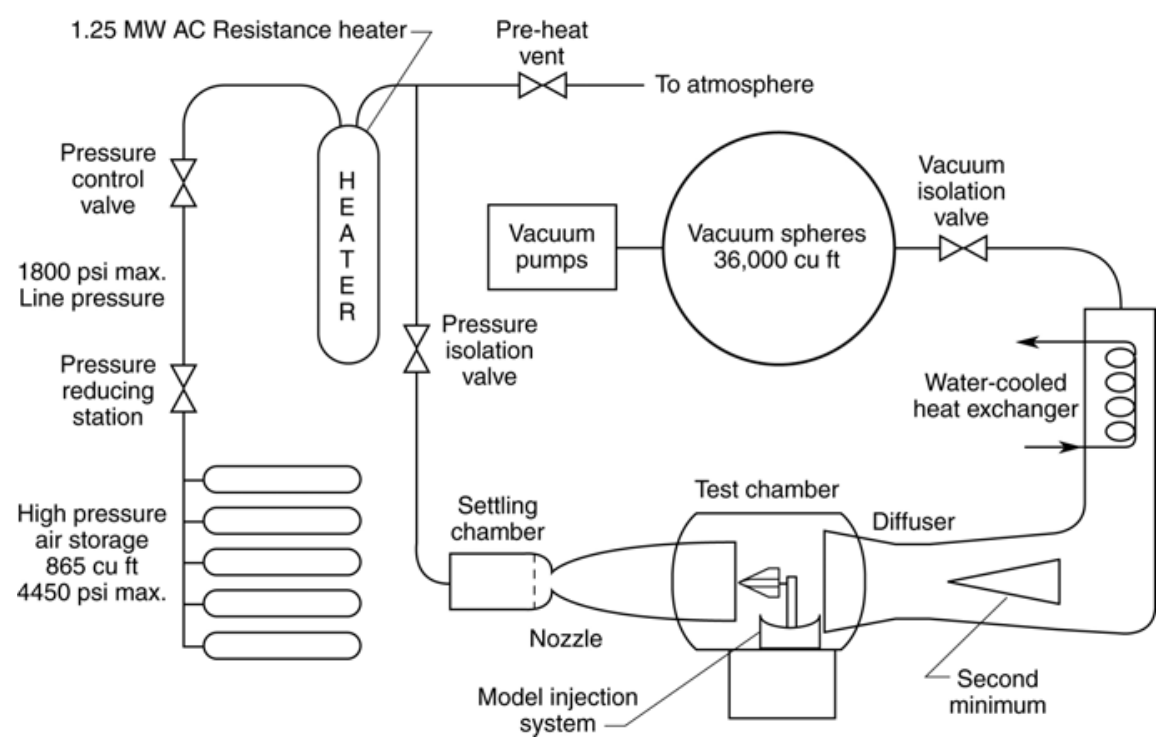

Figure 10. Schematic of the NASA Langley 15-Inch Mach 6 High Temperature Tunnel.

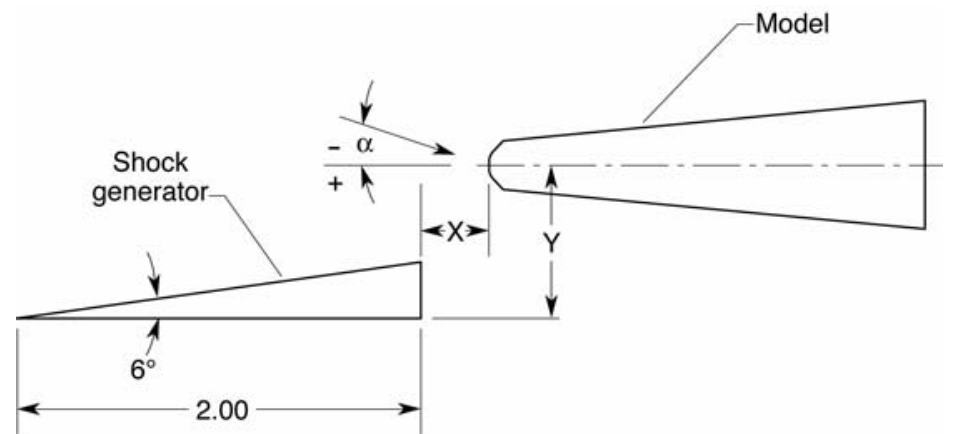

Figure 11. Relative positions of the model and shock generator.

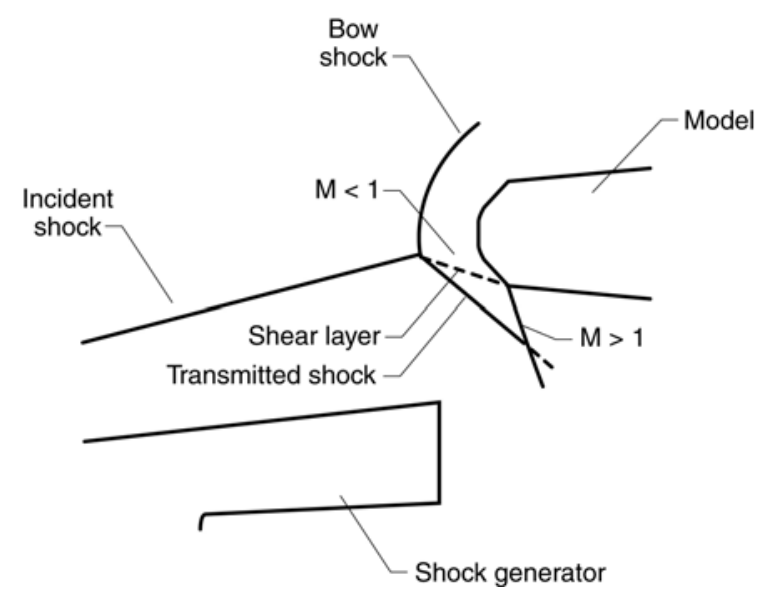

(a) Schematic diagram

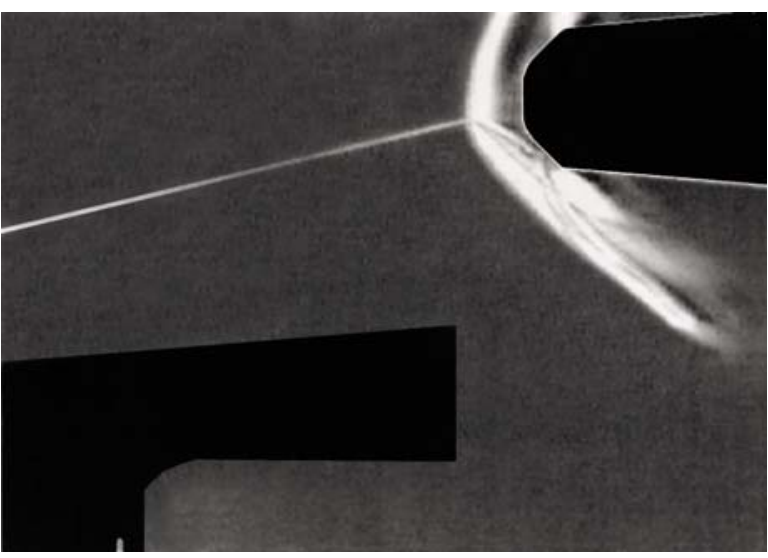

(b.) Focusing schlieren image. (run 9, $\alpha=0^{\circ}$, $\mathrm{m}_{\mathrm{j}} / \mathrm{m}_{\infty}=0.0, X=0.100$ in., $\mathrm{Y}=0.549$ in., $\operatorname{Re}_{\infty}=4.00 \times 10^{6} \mathrm{ft}^{-1}$ )

Figure 12. Type III shock interaction pattern. 


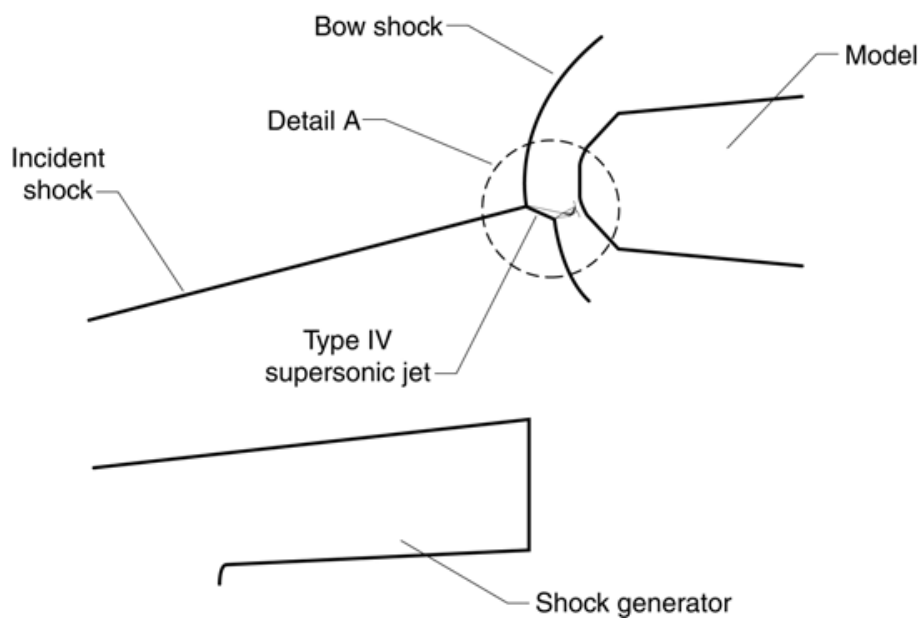

Figure 13. Schematic of type IV shock wave interference pattern.

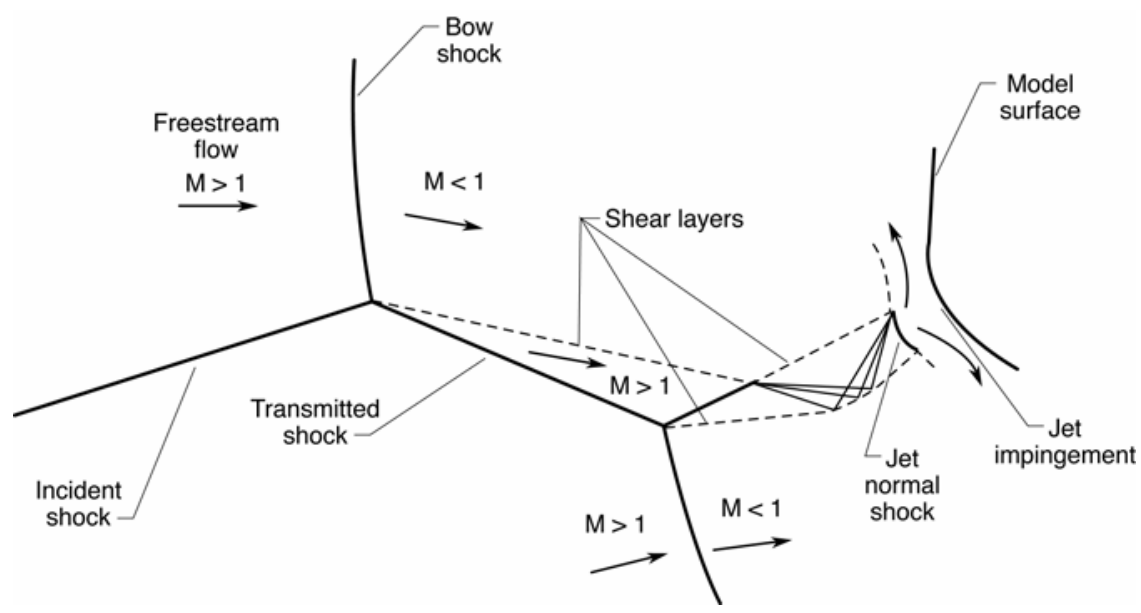

Figure 14. Schematic of type IV supersonic jet interference pattern. (Detail A of figure 13.)
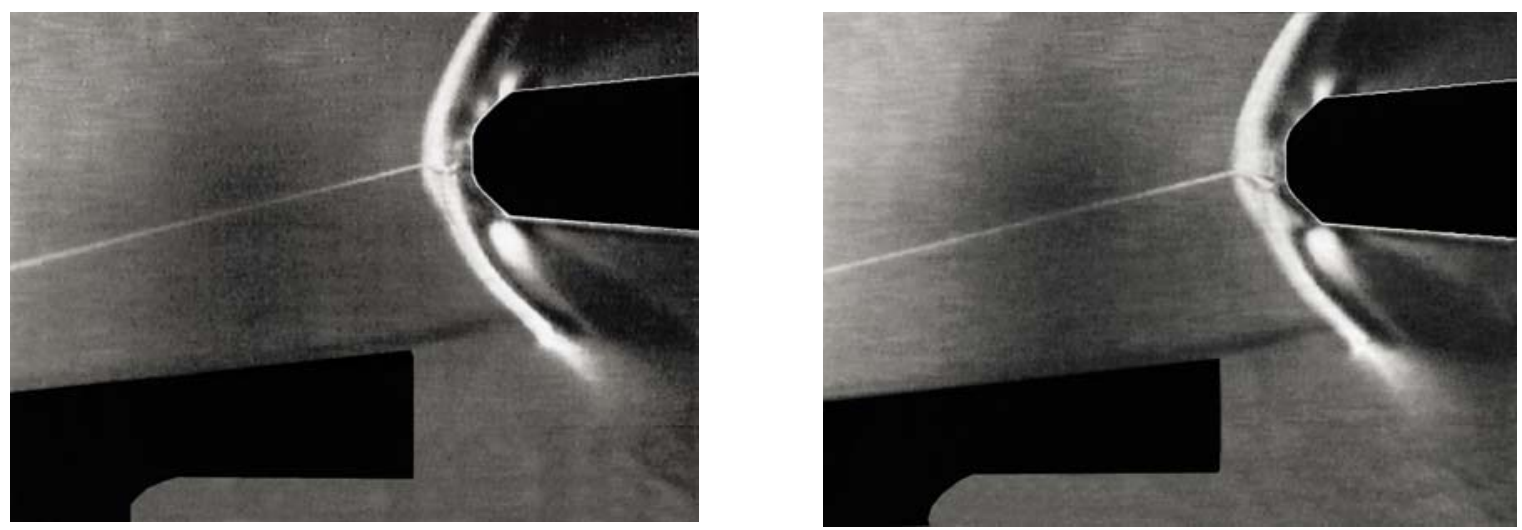

Figure 15. Focusing schlieren images of type IV interference patterns obtained at 1.4 seconds apart. (run 6, $\alpha=0^{\circ}, \mathrm{mj}_{\mathrm{j}} / \mathrm{m}_{\infty}=0.0, \mathrm{X}=0.100$ in., $\mathrm{Y}=0.526$ in., $\operatorname{Re}_{\infty}=4.06 \times 10^{6} \mathrm{ft}^{-1}$ ) 


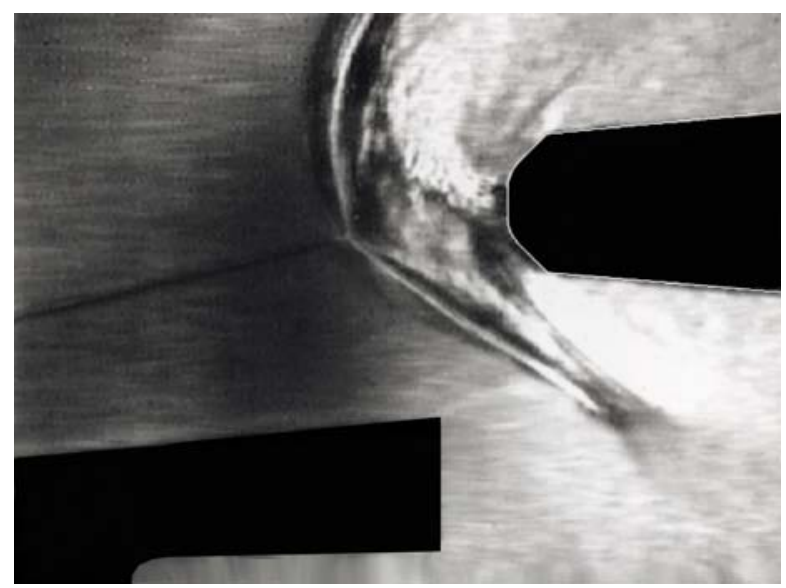

(a.) Focusing schlieren image.(run $7, \alpha=0^{\circ}$, $\mathrm{m} / \mathrm{m}_{\infty}=0.503, X=0.100$ in., $Y=0.532$ in., $\operatorname{Re}_{\infty}=4.31 \times 10^{6} \mathrm{ft}^{-1}$ )

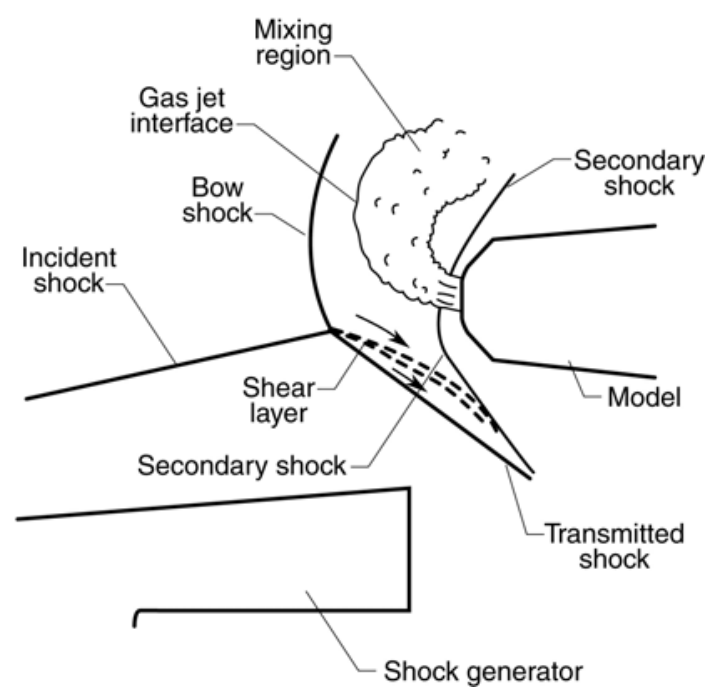

(b) Schematic diagram.

Figure 16. Modified Type III shock wave interference pattern with gas injection.
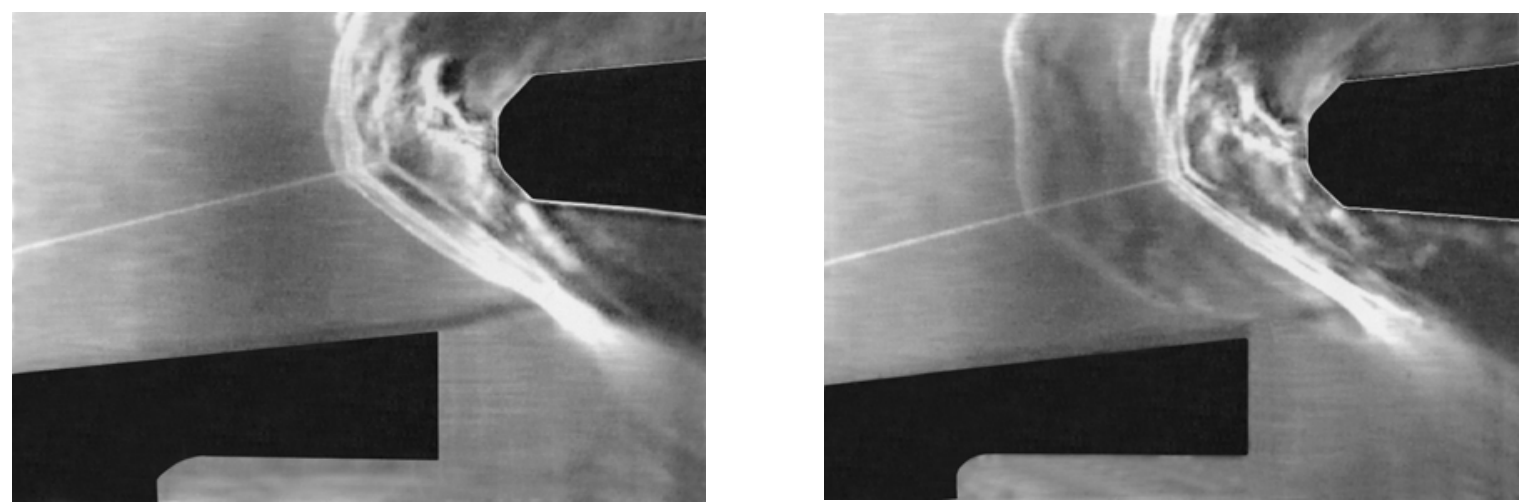

Figure 17. Focusing schlieren images of modified Type III shock interference patterns with gas injection. Images obtained at 0.033 seconds apart. (run $\alpha=0^{\circ}, \mathrm{mj}_{\mathrm{j}} / \mathrm{m}_{\infty}=0.516, \mathrm{X}=0.100$ in., $\mathrm{Y}=$ 0.526 in., $\operatorname{Re}_{\infty}=4.06 \times 10^{6} . \mathrm{ft}^{-1}$ )

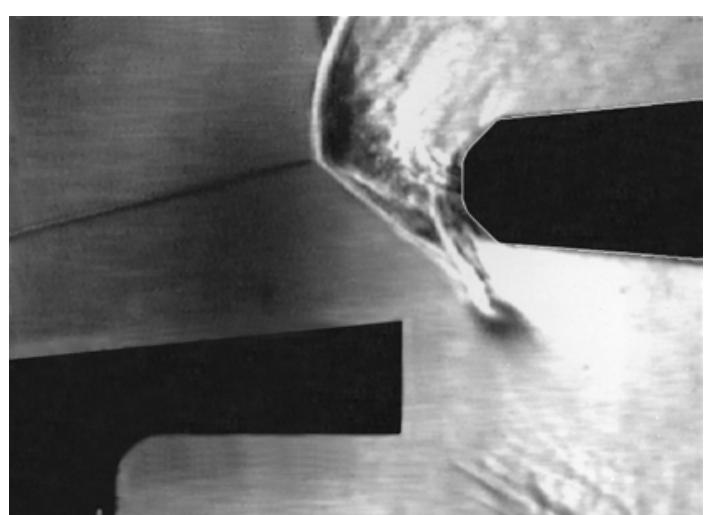

(a.) Modified Type III shock interference before transition ( $\mathrm{Y}=0.438$ in.)

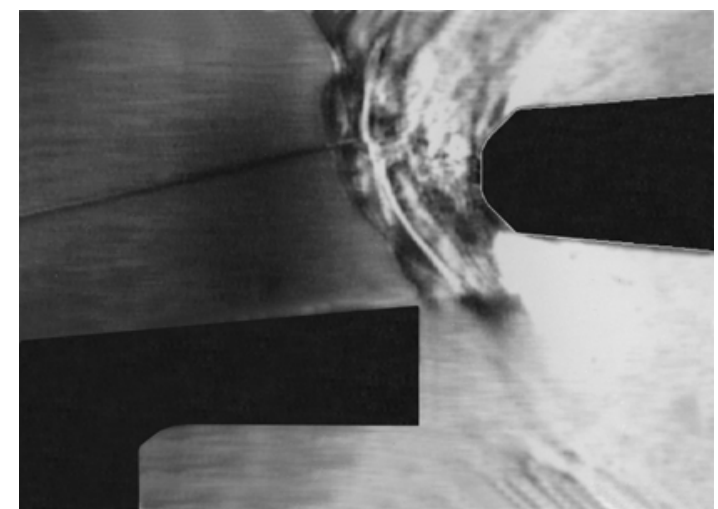

(b.) Modified Type IV shock interference after transition ( $\mathrm{Y}=0.430 \mathrm{in}$.)

Figure 18. Focusing schlieren images of shock interaction transition with gas injection (run 7 , $\alpha=0^{\circ}, \mathrm{mj}_{\mathrm{j}} / \mathrm{m}_{\infty}=0.503, \mathrm{X}=0.100$ in., $\operatorname{Re}_{\infty}=4.31 \times 10^{6} \mathrm{ft}^{-1}$ ) 

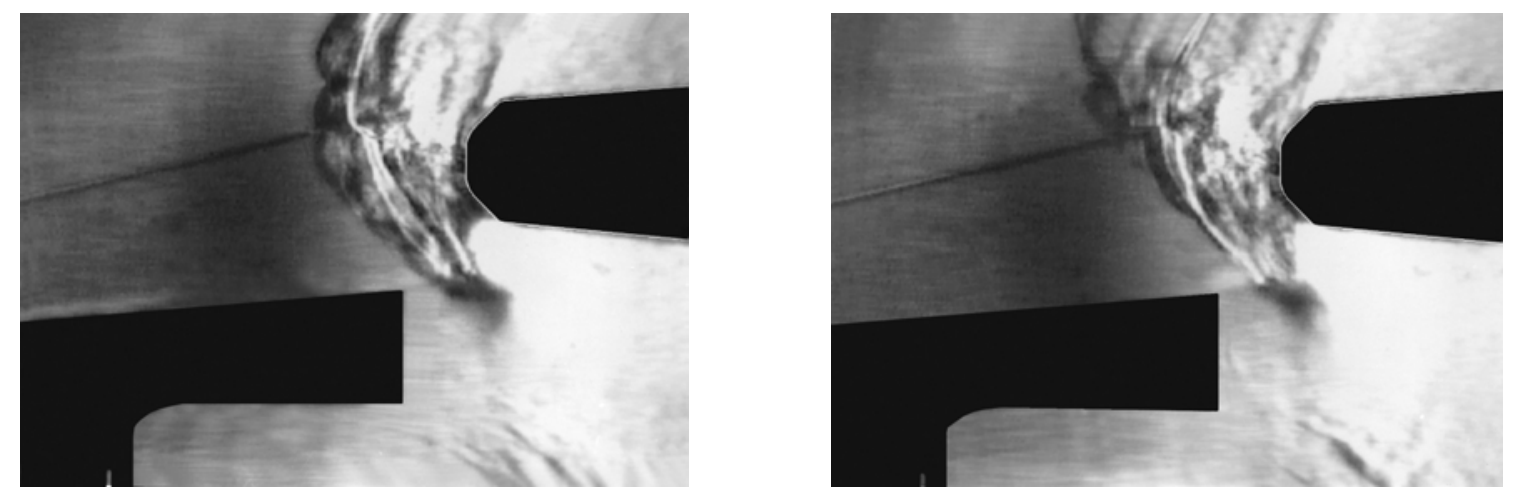

Figure 19. Focusing schlieren images of modified Type IV shock interference pattern with gas injection. Images obtained at $0.4 \mathrm{sec}$. apart. (run 7, $\alpha=0^{\circ}, \mathrm{m} / \mathrm{m}_{\infty}=0.503$, $X=0.100$ in., $Y=0.422$ in., $\operatorname{Re}_{\infty}=4.31 \times 10^{6} \mathrm{ft}^{-1}$ )

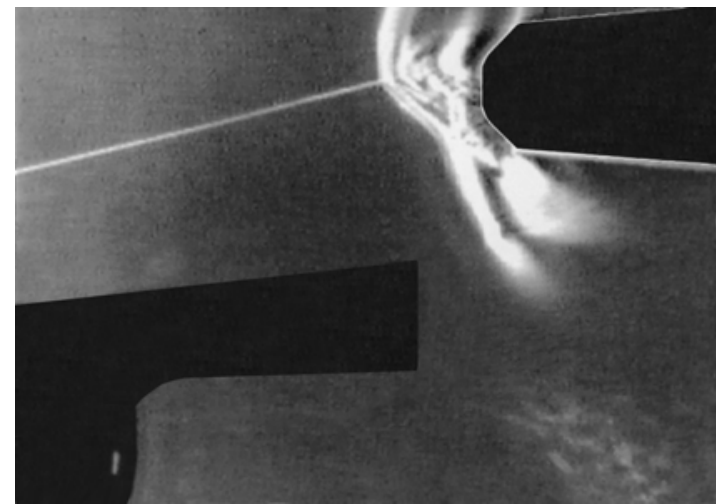

(a.) Modified Type III shock interference before transition. ( $Y=0.472$ in.)

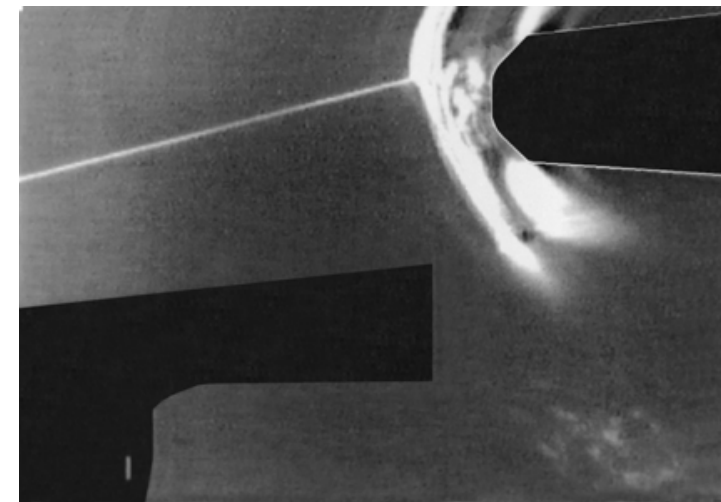

(b.) Modified Type IV shock interference after transition. ( $Y=0.467$ in.)

Figure 20. Focusing schlieren images of shock interaction transition with gas injection (run 8 , $\alpha=0^{\circ}, \mathrm{mj}_{\mathrm{j}} / \mathrm{m}_{\infty}=0.336, \mathrm{X}=0.100$ in., $\operatorname{Re}_{\infty}=4.34 \times 10^{6} \mathrm{ft}^{-1}$ )

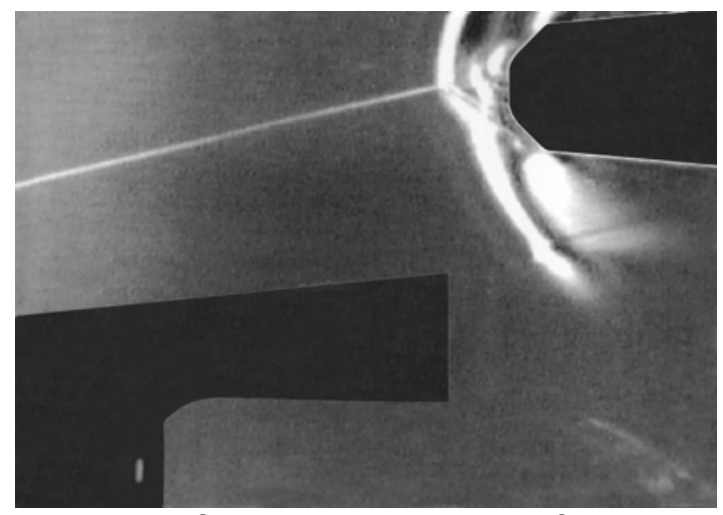

(a.) Modified Type III shock interference before transition $(Y=0.502$ in)

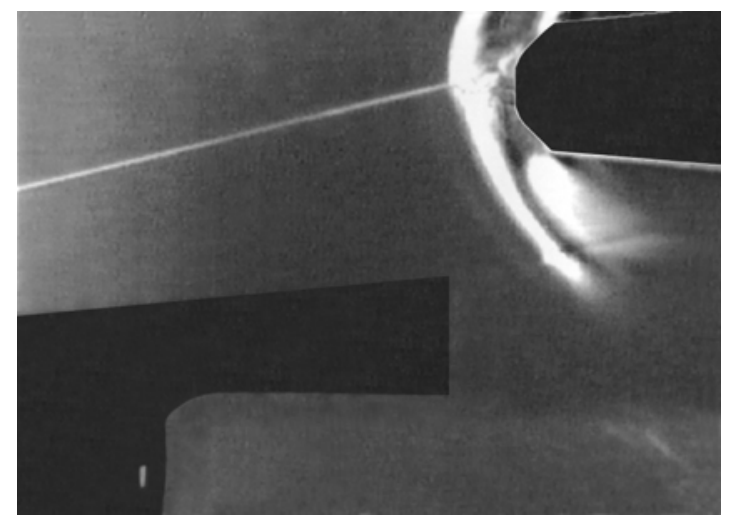

(b.) Modified Type IV shock interference after transition. ( $Y=0.500$ in.),

Figure 21. Focusing schlieren images of shock interaction transition with gas injection (run 9, $\alpha=0^{\circ}, \mathrm{m}_{\mathrm{j}} / \mathrm{m}_{\infty}=0.174, \mathrm{X}=0.100 \mathrm{in}$., $\operatorname{Re}_{\infty}=4.00 \times 10^{6} \mathrm{ft}^{-1}$ ) 


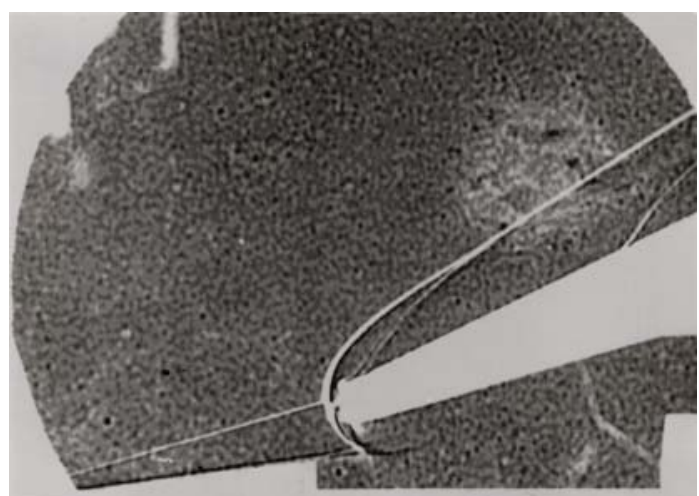

(a) Test section window flaws visible.

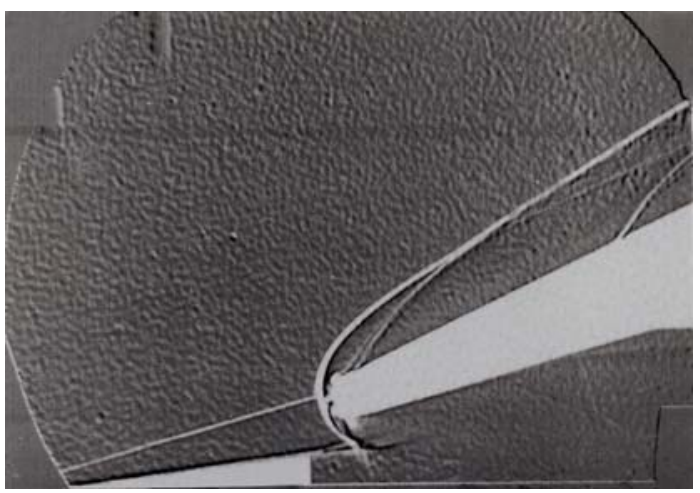

(b) Test section window digitally subtracted.

Figure 22. Conventional schlieren image of a Type IV shock interference pattern without gas injection. (run $16, \alpha=-20^{\circ}, \mathrm{m}_{\mathrm{j}} / \mathrm{m}_{\infty}=0.0, X=0.180$ in., $Y=0.808$ in., $\operatorname{Re}_{\infty}=4.13 \times 10^{6} \mathrm{ft}^{-1}$ )

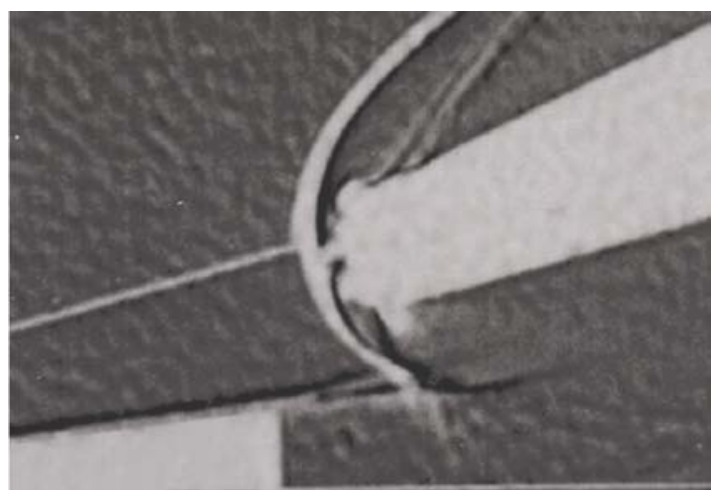

(a) no gas injection

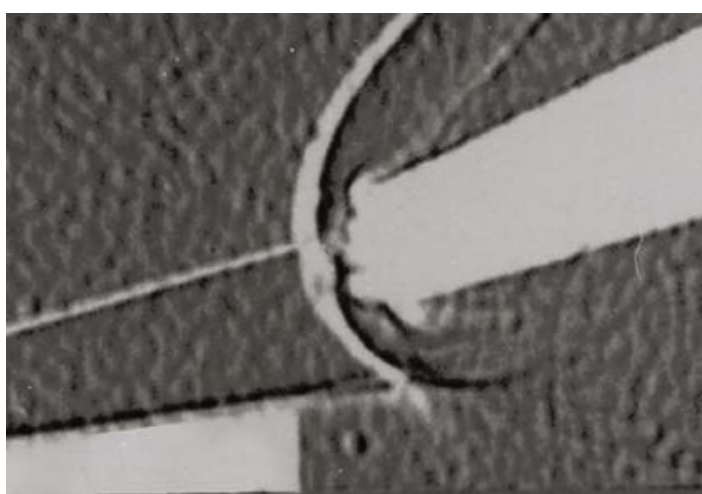

(b) Gas injection $\left(\mathrm{m}_{\mathrm{j}} / \mathrm{m}_{\infty}=0.339\right)$

Figure 23. Close-up conventional schlieren images of shock interference patterns with the test section window digitally subtracted. (run $16, \alpha=-20^{\circ},, X=0.180$ in., $Y=0.808$ in., $\operatorname{Re}_{\infty}=4.13 x$ $10^{6} \mathrm{ft}^{-1}$ ) 